\title{
Influence of Key Macroeconomic Factors on the Dynamics of Employment of the Population of the Russian Federation
}

\author{
E. A. Edinak* \\ Institute of Economic Forecasting, Russian Academy of Sciences, Moscow, Russia \\ *e-mail: edinak_e@mail.ru \\ Received January 12, 2021; revised January 20, 2021; accepted February 25, 2021
}

\begin{abstract}
The article analyzes the influence of such macrostructural factors as final demand and a group of structural and technological factors on the dynamics of employment of the population of the Russian Federation on the basis of the input-output balance. The latter includes changes in labor productivity and production technologies, which is reflected in changes in the elements of the matrix of direct cost coefficients. Estimates of the contribution of these factors to the dynamics of employment during periods of transformational recession (1991-1998), subsequent recovery growth (1999-2014) and stagnation (2015-2017) are calculated.
\end{abstract}

Keywords: employment, labor market, intersectoral balance, structural shifts, factor analysis, unemployment DOI: $10.1134 / \mathrm{S} 1075700721040080$

Introduction. The article presents the results of the analysis of the impact on the dynamics of employment of the population of the Russian Federation of such macrostructural factors as final demand, and a group of structural and technological factors.

The need for such research is due to a number of reasons. First, the dynamics of the employed population is largely determined by the dynamics of the country's GDP/output. Despite the high flexibility of the Russian labor market, the operation of the protective mechanisms of the labor market enshrined in the Labor Code of the Russian Federation and the stereotypes of employers' behavior that developed back in Soviet times ${ }^{1}$, periods of economic downturn are accompanied by a decrease in the number of employees, while during an economic recovery, the demand for labor increases. So, during the period of market reforms 1991-1998, in the country, a significant decrease in the number of employed people was recorded, accompanied by changes in its structure, and at the same time an increase in unemployment. Subsequent economic growth up to 2009 was accompanied by a gradual increase in the number of people employed in the economy and the stabilization of its structural characteristics against the background of a

\footnotetext{
${ }^{1}$ They are aimed at avoiding layoffs of employees during the crisis through wage adjustments (see, for example, [1-3]), the use of part-time employees, sending on unpaid leave, and other forms of so-called "hidden unemployment." It should be noted that in 2020 , during the coronavirus crisis, the measures and volumes of state support for business depended on the personnel policy of enterprises and encouraged them to maintain the precrisis number of employees as much as possible.
}

decrease in unemployment (Fig. 1). The period of slowdown in economic dynamics (2011-2018) was characterized by a relatively constant number of employees, while unemployment declined.

If the volume of GDP by 2019 exceeded the value of 1990 by a quarter, then the number of employed decreased by $10 \%$ over this period, which is due, among other things, to demographic trends.

Second, the number and structure of the employed population directly depend on such structural characteristics of the economy as the level of its technological development, production volume, its sectoral and spatial structure, investments, the share of imports in final and intermediate consumption, proportions between elements of final demand, etc. And in this regard, it is important to understand what factors in the retrospective period most influenced the size and dynamics of the employed population and how the nature of this influence changed over time.

Note that the need for a macrostructural approach to the analysis and forecast of labor market dynamics is most often necessary when the question once again arises of whether there is enough labor force (both within the country and taking into account foreign labor migrants) to achieve certain the rate of economic growth in the long term. It is obvious that the quantity, quality and structural characteristics of labor resources may be one of the constraints on the increase in the rate of economic dynamics. If we understand the configuration and contribution of macroeconomic factors to ensuring the rate of economic growth in relation to the dynamics of employment in retrospect, then on this basis, some forecast 


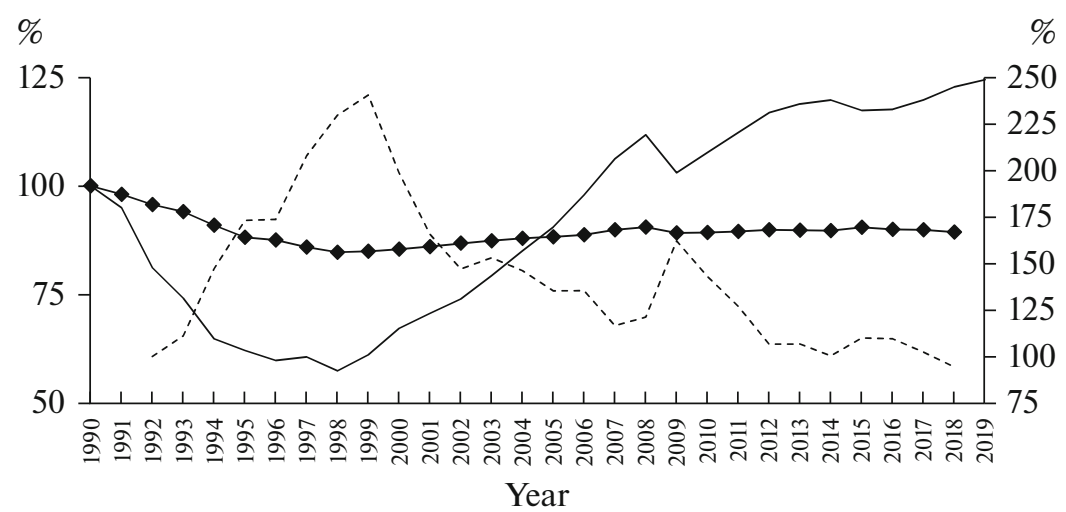

Fig. 1. Dynamics of GDP, employed and unemployed population in the Russian Federation in 1991-2019, 1990=100\%. - GDP; - - the number of employees; -- - the number of unemployed (right axis) $1992=100 \%$. Source: Rosstat data.

estimates from the side of labor demand (as well as its quantitative, qualitative, spatial and sectoral proportions) are possible. Comparison of these estimates with the supply of labor (the prospective estimates of which can be based, for example, on a demographic forecast) reveals the constraints on the part of labor resources that form the requirements for economic policy in this area.

The Russian labor market is quite naturally an object of comprehensive analysis and study by Russian and foreign scientists. The problem of mismatch in the economy of the Russian Federation of demand and supply of labor, taking into account its various structural characteristics, the analysis of factors that determine the process of reconciliation of imbalances is widely presented, for example, in [4-7]; analysis of structural changes in employment and income of the population in [8-10]. The influence of the dynamics of the number and the transformation of the structural characteristics of employment (in particular, such as changes in its age composition) on the rate of economic growth is studied, for example, in [11].

However, the focus of these and other works is mainly on the analysis of the labor market and its structural characteristics, as well as on assessing the impact of its dynamics on the rate and quality of economic growth. This paper presents an analysis of the impact of economic dynamics and transformation of the structure of the economy on the number of employed population of the Russian Federation in the retrospective period. Despite the relevance and practical importance of the proposed factor analysis of employment, it seems to us that such studies have not been conducted before.

Methodology for assessing the impact of key macroeconomic factors on the employed population. There are two macroeconomic factors that determine the change in the volume and structure of employment: the dynamics of production and the dynamics of sectoral labor intensity.
Changes in the level of sectoral labor intensity over a long time interval can be caused by structural and technological shifts that affect unit labor costs and are associated, firstly, with the transition to labor-saving technologies within one industry; secondly, with a change in production technologies, entailing shifts in the structure of costs of industries and indicators of the labor intensity of products. In the short and medium term, the degree of utilization of production capacities also affects the intensity of labor use.

In turn, the dynamics and sectoral structure of gross output predetermine changes in the following indicators:

- The volume and structure of final demand (volume and structure of individual elements of final demand: household consumption, government consumption, accumulation of fixed capital, dynamics of stocks, exports).

-The volume and structure of intermediate consumption, which also depend on production technologies and the level of capacity utilization in various sectors.

-The share of imports in final and intermediate consumption.

Consideration of individual elements of GDP, the size and structure of intermediate consumption and imports, allows us, in the retrospective period, to determine the degree of influence of each of these elements on employment indicators.

To study the influence of the listed macroeconomic factors on the dynamics of employment, a special toolkit is needed to clearly demonstrate the contribution of each factor to the change in this indicator in retrospect. This requirement is most fully met by the intersectoral balance (ISB) toolkit ${ }^{2}$, which is an information and analytical system that reflects the contribution of the most important macroeconomic indica-

\footnotetext{
${ }^{2}$ Hereinafter, the input-output symmetric table is understood as the input-output balance.
} 
tors to the formation of the country's gross output and GDP. In terms of ISB, the change in production technologies is reflected through the elements of the direct cost matrix.

To analyze the impact of structural changes in the economy on employment, we used the series of inputoutput balances developed at the Institute of Economic Forecasting of the Russian Academy of Sciences for 1990-2017 at current and constant prices. For the period 2011-2017, balances are harmonized with the official publications of Rosstat input-output tables.

Determination of the influence of the selected factors on the dynamics of employment based on the ISB is possible by means of the equation of the static model of the input-output balance:

$$
L=L / X X=L / X(E-A)^{-1} Y,
$$

where $L$ is the vector of sectoral employment $\left(L_{i}\right.$, employment in $i$ th branch of the Russian economy); $X$, the vector of industry issues $\left(X_{i}\right.$, the output in the $i$ th industry); $L / X$ is the vector of labor intensity; $\left(L_{i} / X_{i}\right.$, labor intensity of output of the $i$ th industry); $A$ is the matrix of coefficients of direct costs; $Y$ is the final demand for domestic products $(Y=C+H+I+E x)$; $C$ is household consumption; $G$ is government consumption of products; $I$ is investment consumption and increase in stocks of products; $E x$ is exports).

To take into account the influence of the import component in intermediate and final consumption on the dynamics of employment, the elements of intermediate and final demand are "cleared" of imports.

With the help of input-output balances for 19902017 , it is possible to decompose the change in employment into components corresponding to the change in the macroeconomic factors taken into account in the model. In this case, one should adhere to the logic of a step-by-step transition of indicators for the study period. This means that within the framework of one iteration of calculations, changes in time of only one factor are taken into account, while the others remain unchanged (fixed) at the level of the base year.

The calculations used the following sequence of steps to assess the contribution of the factors under consideration:

-The volume and structure of household consumption.

-The volume and structure of government consumption.

-The volume and structure of the accumulation of fixed capital.

-The volume and structure of exports.

-The share of imports in final and intermediate consumption.

- Coefficients of direct costs.

-Sectoral labor intensity.
The contribution of each factor was estimated as the difference between the previous estimate of the number of employed and the one obtained as a result of the transition to the next step. The calculated balances of the INP RAS used in the analysis in the context of types of economic activities (FEA) have a dimension of $44 \times 44$.

This approach was used earlier to analyze the impact of structural changes in the economy on the dynamics and structure of output. The results of this analysis are given, including in [12, 13].

Analysis of the influence of key macroeconomic factors on the employed population. The corresponding calculations were performed for two time periods: the transformational recession (1990-1998) and the subsequent (1999-2017), including the period of recovery growth (1999-2014), followed by the ongoing stagnation.

Shown in Fig. 2 in aggregated form, the calculation results show that the periods under consideration are characterized by different directions and the influence of key macroeconomic factors on the number of employed ${ }^{3}$.

During the transformational recession, during which the number of employed decreased by 12.2 million. (from 80.1 to 67.8 million people), the dynamics of only one factor actually acted in the direction of increasing the number of employed. This is an increase in sectoral labor intensity (which was facilitated by a precipitous drop in output in the economy with a less severe reduction in employment due to the abovementioned protective mechanisms of the labor market). The dynamics of all the other factors under consideration during this period influenced the decline in employment.

In the subsequent period, during which employment increased by four million people. (from 68 to 72 million people), the direction and impact of factors changed. All elements of final demand "contributed" to the growth of employment, while the share of imports in intermediate and final consumption and labor productivity, on the contrary, reduced the demand for labor (employment). The analysis showed that structural and technological changes, measured using direct cost ratios, had minimal impact on employment during both periods.

As already noted, each of the two periods under consideration contains qualitatively different intervals, especially the period 1999-2017. In this regard, it is necessary to analyze in more detail the impact of the factors under consideration on the dynamics of employment within each time interval.

\footnotetext{
${ }^{3}$ Hereinafter, under the influence of a particular factor on the number of employed, an analysis is meant under "other things being equal", i.e., assessment of the impact of the acroeconomic factor on employment, provided that all other parameters of the economy remain unchanged, at the level of the base year.
} 

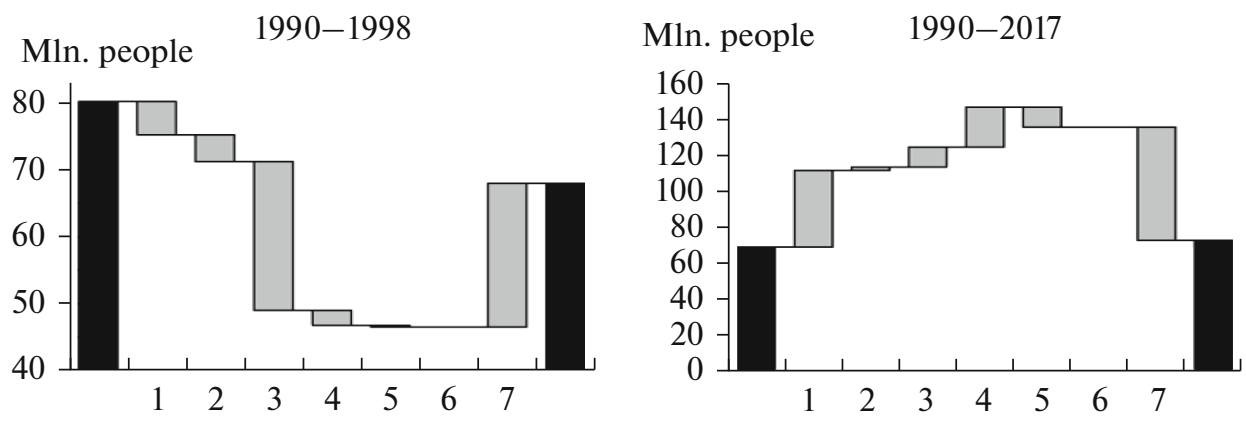

Fig. 2. Change in the number of employed under the influence of changes in the factors under consideration: (1) volumes and structure of household consumption; (2) volumes and structures government consumption; (3) volumes and structure of fixed capital accumulation; (4) volumes and structure of exports; (5) the share of imports in the final and intermediate consumption; (6) coefficients of direct costs; (7) industry-specific labor intensity.
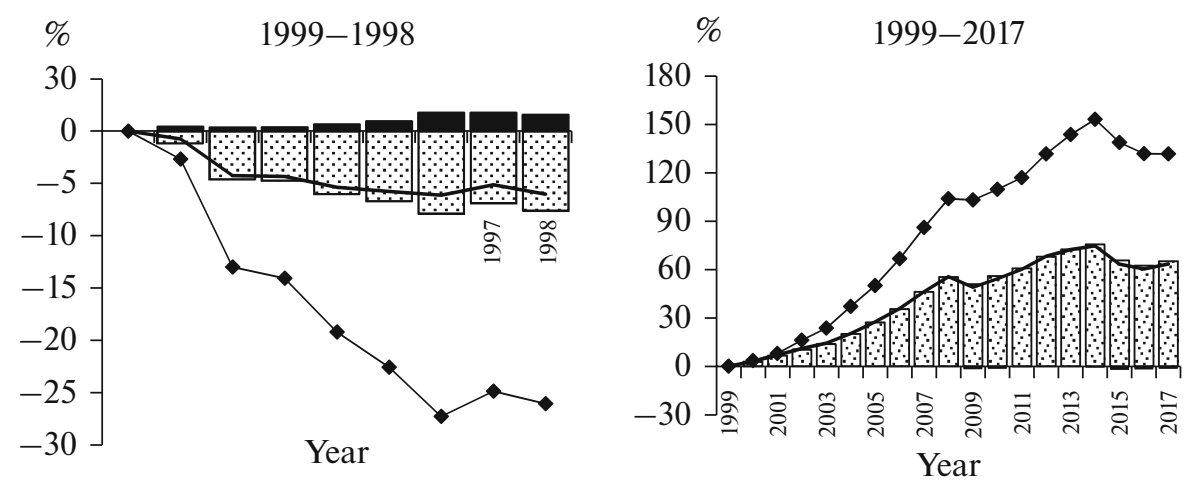

Fig. 3. Impact of changes in volumes and structure of consumption $\square$ households by the number of employed quality component; $:$ quantitative component; - employment, total; $-\bullet-$ household consumption.

The fall in household consumption in 1990-1998 by $26 \%$ in comparison with the volumes in 1990 was the result of both a sharp decline in household incomes and transformations of the price structure [12]. This factor acted in the direction of reducing employment during this period (all other things being equal, the contraction of household consumption volumes led to a decrease in employment during this period by $6 \%$ ). Moreover, the toolkit used makes it possible to separately assess the contribution of the quantitative component (change in household consumption volumes) and the qualitative component (change in the consumption structure). During the period under review, the change in the structure of consumption acted, on the contrary, in the direction of supporting the volume of employment by replacing the products of less laborintensive industries with products of industries with a higher labor-intensity (Fig. 3).

Among the most noticeable changes in the period under review, it should be noted the growth of consumption (percent): products of the sectors "agriculture and forestry, hunting and fishing" +3.8 (in the consumption structure) and "wholesale and retail trade, repairs" +1.9 , and a decrease in consumption of food products -3.2 , textile and clothing production -5.2 .

The period 1999-2017, on the contrary, was characterized by a positive impact on the growth of household consumption, which expanded due to the growth of incomes both in the economy as a whole and the income of the population. During the period under review, household consumption increased 2.3 times compared to 1999 , which contributed to the expansion of employment (by 63\%), primarily due to the quantitative component, while the structural component had a minimal effect on employment. The 2009 crisis stabilized the consumption volumes at the level of the previous year, while the 2014 crisis resulted in a reduction in consumption volumes, which in turn affected the decline in employment.

A similar effect in the periods under consideration was exerted by the scale and structure of government consumption. A decrease in its physical volume in 1990-1998, caused by a reduction in budget revenues during this period, had a negative impact on employment (Fig. 4). This negative impact was partly offset by a change in the structure of government consumption: the share (but not volumes) of spending on education, 

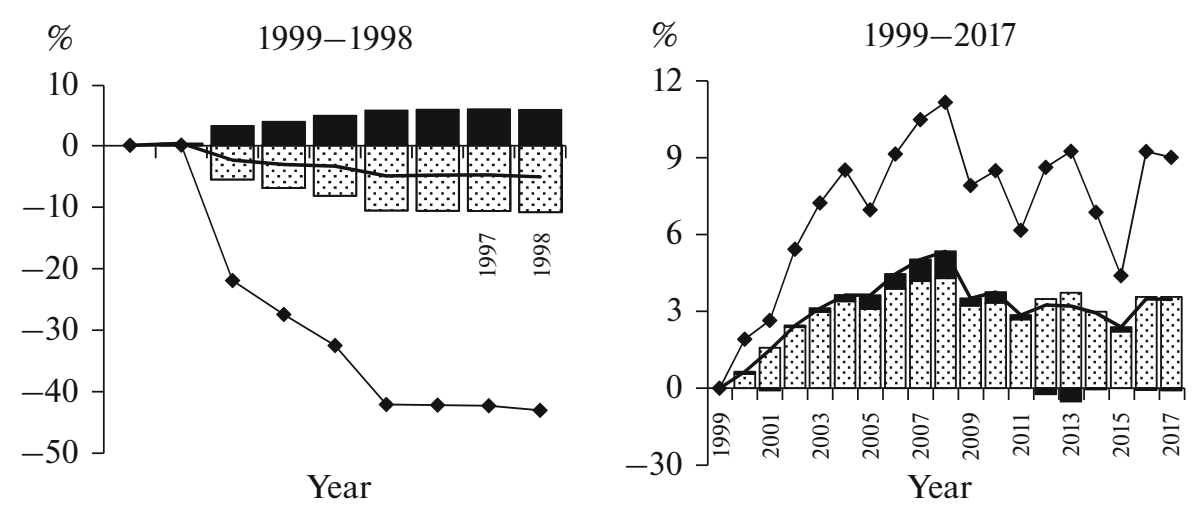

Fig. 4. The impact of changes in the volume and structure of government consumption on the number of employed $\square$ quality component; $:-$ quantitative component; - employment, total; $-\bullet-$ government consumption
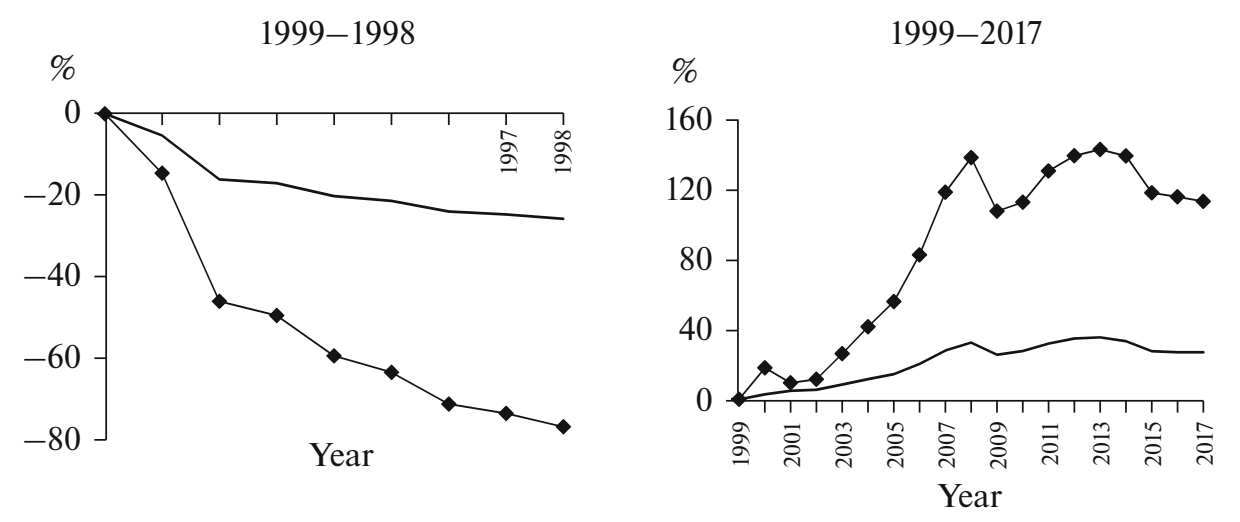

Fig. 5. Influence of changes in the volume of accumulation of fixed capital on the number of employees - employment, total; -- investments.

health care and public, social and private services (sectors traditionally labor-intensive in the Russian economy) increased.

In the subsequent time interval (1999-2017), three periods of a decrease in government spending were recorded $(2005,2009-2011,2014-2015)$, which acted to reduce employment. It should also be noted that the growth of government spending in 2012-2013 did not affect the increase in employment, primarily due to the reduction in the share of spending on public administration and defense, education and health care.

A decrease in the physical volumes of fixed capital accumulation, which was traditional during the period of economic downturn, was the factor that had the strongest negative impact on employment (for the period 1991-1998, by a quarter compared with the number in 1990). It could only be prevented by the policy of artificially preserving employment at enterprises by reducing labor costs (Fig. 5).

The growth in the accumulation of fixed capital in the subsequent recovery period had the same strength, but opposite in direction, on employment (in general, for the period 2000-2017 an increase by a quarter compared to the 1999 level). The decline in the volume of fixed capital formation in the crisis years of 2009 and 2014-2015 acted, ceteris paribus, towards the reduction of employment in the economy. At the same time, the qualitative component (change in the sectoral structure of investments) did not actually affect employment during both periods under consideration.

The dynamics of exports in the period 1991-1998 was characterized by a reduction in physical volumes in the first half of the decade and subsequent moderate recovery (primarily due to the raw materials sectors) (Fig. 6).

The decline in the physical volume of exports was a factor that had a negative impact on employment, while the change in the structure of exports, on the contrary, offset the negative effect. By 1997, metallurgical and chemical production reoriented from the domestic to the foreign market, increasing their share in the export structure compared to the base year, which also had a positive effect on the stability of the number of employees. However, compared with the impact of the factor of fixed capital accumulation 

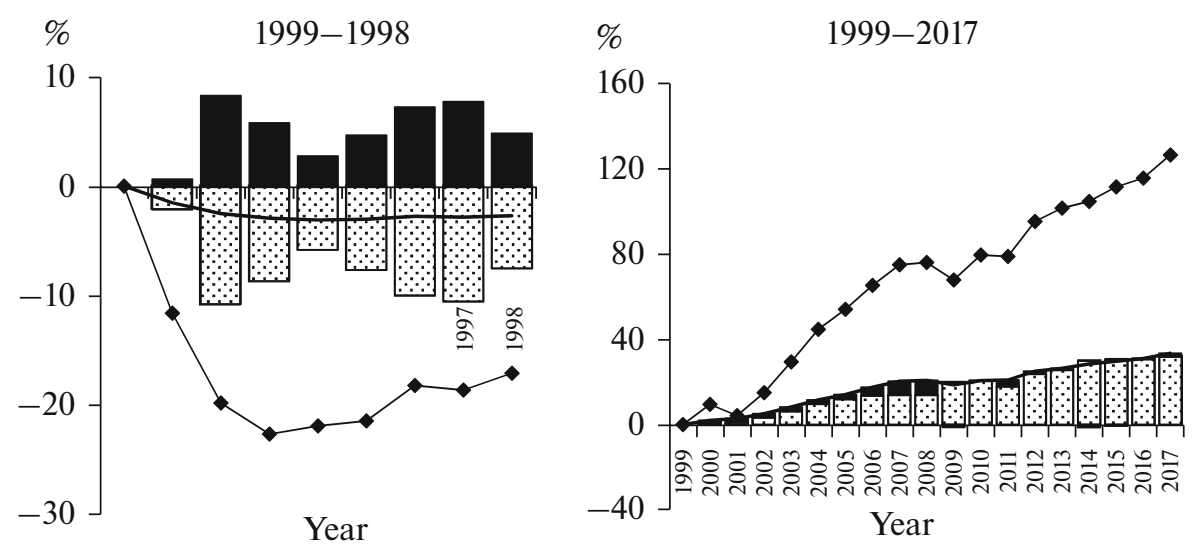

Fig. 6. The impact of changes in the volume and structure of exports on the number of employees: $\therefore$ quantitative component; - employment, total; $-\bullet-$ export.

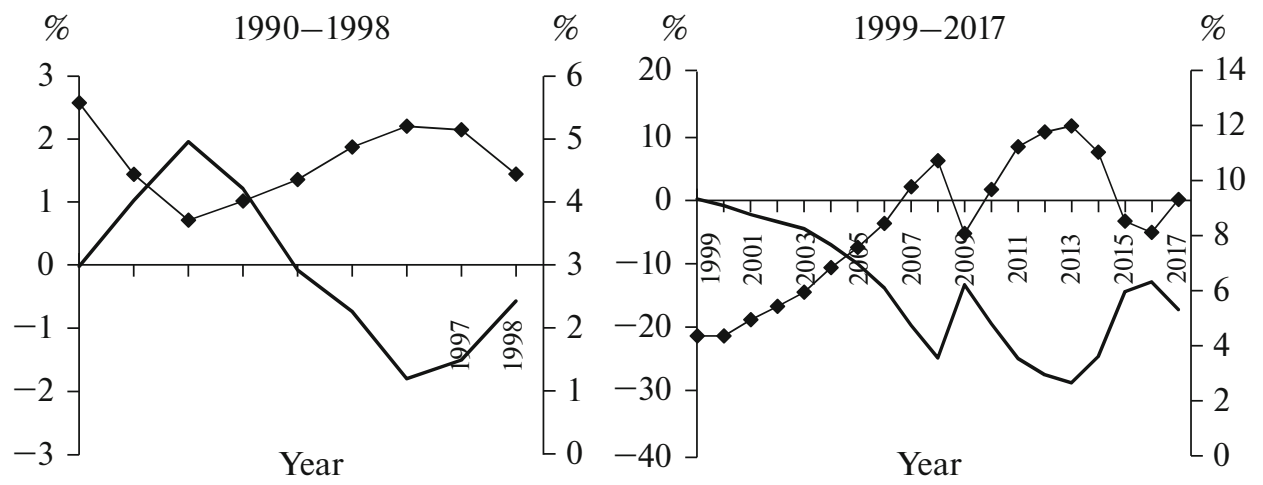

Fig. 7. The impact of changes in the share of imports in domestic consumption on the number of employed: - employment, total;

- - share of imports in domestic consumption (right axis)

during the transformational recession, the impact of exports on the employed population was not significant.

The subsequent rapid growth in exports, driven by the rise in prices on world commodity markets, was a factor contributing to the growth of the employed population.

A decrease in imports of intermediate and final products was a factor in the increase in the number of employed, while the growth of imports in domestic consumption put pressure on employment towards its reduction (Fig. 7). For the period 1990-1998, insignificant fluctuations in the share of imports in output are characteristic, the value of which did not exceed $6 \%$ over the entire period. Thus, from the point of view of the impact on employment, this factor did not play a significant role.

In the subsequent recovery period, the growth of imports caused by an increase in domestic demand on the basis of an increase in household incomes, while maintaining the low competitiveness of domestic goods, had a negative impact on employment. However, the decline in the share of imports in domestic consumption, observed during the crisis periods (2009 and 2014-2016), served as a factor contributing to the growth of employment. For the period 1999-2017 the contribution of this factor to the decline in employment amounted to $17.2 \%$ of the number of employed in the base year 1998.

As noted above, the influence of the structural and technological factor on employment during both time periods was minimal. Quantitatively, it is estimated by the coefficients of direct costs: their change over time reflects the transformation of production technologies, which entails a change in the structure of intermediate consumption.

The period 1990-1998 was characterized by insignificant deviations in the number of employees from the values of the base year (Fig. 8a). Slightly more deviations from the base year are observed during 1999-2017. The restructuring of the economy during the period of recovery growth affected the reduction of the economy's demand for employment. However, from 2008 to 2011, despite the actual decline in employment in 2009 , the structural transformation led 
(a)

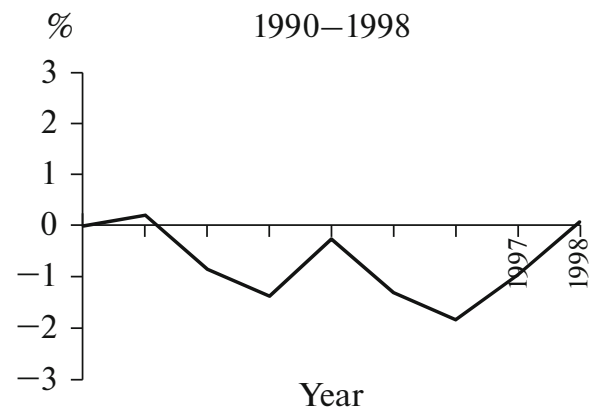

(b)

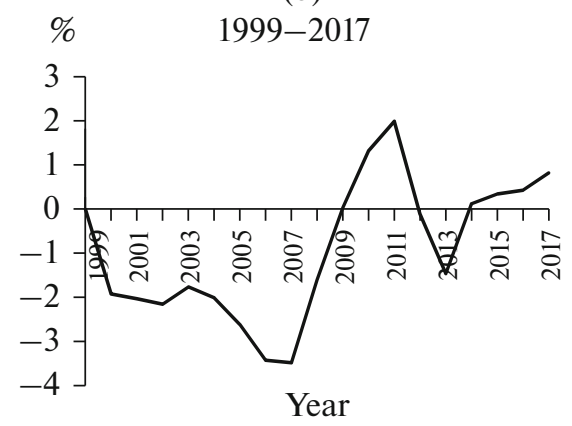

Fig. 8. Influence of the structural and technological factor on the number of employed.

(a)

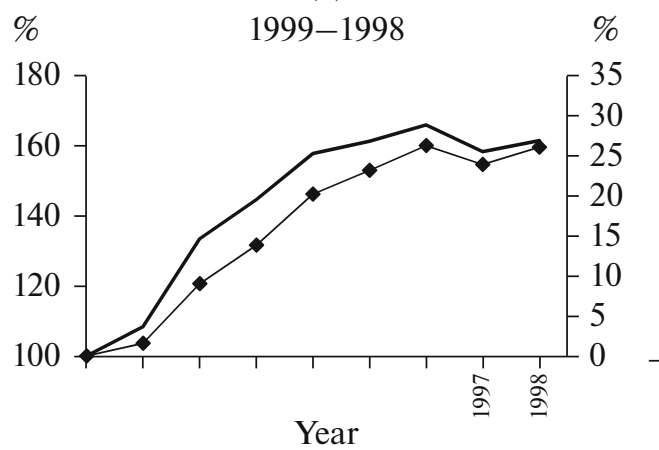

(b)

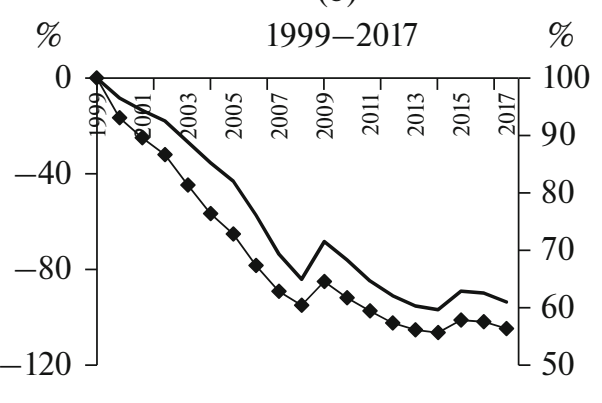

Year

Fig. 9. The influence of the factor of labor intensity on the number of employees: - employment, total; - - labor intensity (right axis).

to an increase in the economy's demand for labor. The same situation was observed in 2014-2017 (Fig. 8b).

The estimates of the impact of the structural and technological factors on employment, obtained in the retrospective period, do not give grounds to expect sharp changes in employment and an increase in the number of structural unemployed caused by technological modernization of the economy in the future, which is currently being actively discussed (see, for example, $[14,15])$. The rationale that technological changes in the economy, in particular those associated with digitalization, will not have an immediate effect on the labor market in the form of a sharp and landslide reduction of jobs, is given in [16].

The magnification of labor intensity as a result of a sharp drop in output during a transformational recession with a much smaller decline in employment, it was, in fact, not a factor in employment growth, but rather a consequence of the protective actions of the labor market and the behavior of enterprises, which, under pressure from the authorities, held back a massive increase in unemployment (Fig. 9a). At the same time, the decrease in the labor intensity of production, caused by an increase in output in the economy, actually doubled with an increase in the number of employed by $6 \%$, was a key limiting factor in the growth of demand for labor on the part of the economy in the period 1999-2017 (Fig. 9b). The role of labor productivity as the main limiting factor in the future increase in the economy's demand for labor has been repeatedly noted in various studies (see, for example, [8, p. 133]).

Conclusions. The calculations presented in the article reveal the nature and depth of the impact of shifts in the sectoral structure of production and the distribution of costs in the economy on the dynamics of the total employed population ${ }^{4}$. Such an analysis of the impact of the considered macroeconomic factors on the dynamics of demand on the foreign labor force is difficult due to the lack of "long," reliable methodology, based on a unified approach, for collecting data on the number of foreign labor migrants in the Russian labor market.

Meanwhile, firstly, similar calculations can be carried out at the sectoral level, with the allocation of factors determining the dynamics of sectoral employment

\footnotetext{
${ }^{4}$ The analyzed number of employed does not contain data on the numbers of the foreign labor force (FLF). Meanwhile, the number of facts of migration registration in 2019 for the purpose of work, according to the Ministry of Internal Affairs of the Russian Federation, amounted to 5.5 million.
} 
in different time periods, which is a separate research task. Secondly, it would be interesting to analyze the impact of these factors on unemployment and the nonlabor force, which would allow a deeper analysis of the structural characteristics of the labor market. This requires estimates of flows between these three states (employment-unemployment-population outside the labor force) at the all-Russian level. Unfortunately, such information is not yet available, while, for example, Eurostat, due to the demand for such statistics from politicians and the public, has been publishing experimental data since $2013^{5}$ on the magnitude and probabilities of population overflow between the three states ${ }^{6}$. The analysis of data published by Eurostat is given, for example, in works [17, 18].

With the availability of relevant information, such an approach would make it possible to quantitatively measure the influence of macroeconomic factors not only on the overall Russian and sectoral number of employees, but also on the change in its educational and professional qualifications. This would provide an opportunity for a deeper study of the relationship between the dynamics of macro indicators, the structural characteristics of the economy and the labor market.

The proposed approach to the factor analysis of the employment of the population of the Russian Federation demonstrates both the subordinate nature of the demand for labor in relation to macrostructural factors, and the connectedness and interdependence of all indicators. Therefore, an understanding of the strength and directions of the relationship between the factors under consideration and the employment of the population in retrospect will allow a comprehensive approach to the problem of forecasting the demand for labor in the economy. This means that within the framework of the macrostructural scenario of the economic development of the Russian Federation, the need for the employed in the economy as a whole and in the context of industries (foreign economic activity) can be determined within the system of interrelated indicators. It is this approach that guarantees the adequacy, validity of forecast estimates of labor demand, and their consistency with other indicators.

\section{REFERENCES}

1. Wages in Russia. Evolution and Differentiation, 2nd ed., Ed. by V. E. Gimpel'son and R. I. Kapelyushnikov (Vyssh. Shk. Ekon., Moscow, 2008) [in Russian].

2. V. Gimpelson, "The labor market in Russia, 20002017,” IZA World Labor, No. 466, 1-13 (2019).

\footnotetext{
${ }^{5}$ The data are experimental in that they are based on regression models and thus rely on the assumptions of these models.

${ }^{6}$ The source of this data is the EU-Labor Force Survey (LFS). Quarterly data on transitions between states of economic activity in the labor market can be viewed on the Eurostat website at: https://appsso.eurostat.ec.europa.eu/nui/show.do?dataset= Ifsi_long_q \& lang = en
}

3. E. T. Gurvich and E. S. Vakulenko, "Research of the Russian labor market and economic policy," Zh. Nov. Ekon. Assots., No. 1, 203-212 (2018).

4. A. G. Korovkin, "Macroeconomic assessment of the state and development prospects of the employment sector and the labor market in Russia," Zh. Nov. Ekon. Assots., No. 1, 168-176 (2018).

5. A. G. Korovkin, "The problems of labor supply and labor demand adjustment on the Russian labor market," Stud. Russ. Econ. Dev. 22, 177 (2011).

6. I. B. Korolev, A. G. Korovkin, I. N. Dolgova, and E. A. Edinak, "Structural aspects within the interaction of employment and education systems in Russia," in Proceedings of the Institute of Economic Forecasting, Russian Academy of Sciences (MAKS Press, Moscow, 2014), pp. 397-425 [in Russian].

7. V. A. Gurtov, E. A. Knyazev, E. A. Pitukhin, L. M. Serova, S. V. Sigova, and N. A. Yurenko, Labor Market Trends under the Influence of the Global Crisis on Russia's Economy and the Role of the Vocational Education System in Staffing the Promising Labor Markets in the Post-Crisis Period. Analytical Report, Ed. by V. A. Gurtov (Petrozavodsk. Gos. Univ., Petrozavodsk, 2009) [in Russian].

8. Transformation of the Structure of the Economy: Mechanisms and Management. Monograph, Ed. by A. A. Shirov (MAKS Press, Moscow, 2018) [in Russian].

9. S. G. Kuznetsov, "Structural shifts in employment and the quality of economic growth," in Proceedings of the Institute of Economic Forecasting, Russian Academy of Sciences (MAKS Press, Moscow, 2020), pp. 504-520 [in Russian].

10. A. A. Shirov and V. V. Potapenko, "The labor market and the quality of human capital," EKO, No. 2, 18-34 (2018).

11. Russian Labor Market through the Lens of Demography. Monography, Ed. by V. E. Gimpel'son and R. I. Kapelyushnikov (Vyssh. Shk. Ekon., Moscow, 2020) [in Russian].

12. M. Yu. Ksenofontov and D. A. Polzikov, "Retrospective structural shifts in the Russian economy," Stud. Russ. Econ. Dev. 29, 625-636 (2018).

13. P. M. Uzyakov, "Toolkit for the input-output analysis of the performance of Russian economy in 1991-2013," Stud. Russ. Econ. Dev. 29, 233-244 (2018).

14. D. Belousov, "Development of the digital ecosystem: Direct and indirect effects for the economy," in V St. Petersburg Economic Congress "Foresight Russia: New Industrial Society. Future” (SPEK 2018) (2018). http://www.forecast.ru/_ARCHIVE/Presentations/ DBelousov/2018-03-31IT-ECO.pdf.

15. S. P. Zemtsov, "Potential robotization and the "ignorance economy' in the regions of Russia," in Abstracts of the XIX April Conference (NRU HSE) (2018). https://doi.org/10.13140/RG.2.2.11496.98567

16. E. A. Edinak, "Influence of structural changes in the economy on the dynamics of jobs," EKO, No. 6, 131$148(2020)$. https://doi.org/10.30680/ECO0131-7652-2020-6-131-148

17. F. Espelage (Eurostat), "Measuring ILO status transitions for the EU: First interesting results," in 8-th Workshop on LFS Methodology (Gdansk, 2013), p. 6.

18. H. Kiiver and F. Espelage, "The use of regression models in labour market flow statistics," in European Conference on Quality in Official Statistics (Q2016) (Madrid, 2016), p. 10. 